\title{
Cloud computing in government organizations: towards a new comprehensive model
}

\author{
Naif Al Mudawi \\ dept. of Computer science \\ University Najran \\ dept.of Informatics \\ University of Sussex \\ Brighton, United Kingdom \\ N.Al-mudawi@sussex.ac.uk
}

\author{
Natalia Beloff \\ dept. of Informatics \\ University of Sussex \\ Brighton, United Kingdom \\ N.Beloff@sussex.ac.uk
}

\author{
Martin White \\ dept. of Informatics \\ University of Sussex \\ Brighton, United Kingdom \\ M.White@sussex.ac.uk
}

\begin{abstract}
Cloud computing is a new information technology paradigm, one which has been adopted in many different sectors. Many developing countries are working on improving e-government to provide services to their citizens that are integrated and effective. Therefore, the Saudi government has made improving e-government a high priority. The aim of this study is to explore significant factors affecting the adoption of cloud computing in e-government services in Saudi Arabia as a case study. After identifying these factors, we propose a new comprehensive model for the Adoption of Cloud Computing in Saudi G-GOVernment (ACCE-GOV) that has been adopted from the Technology Organisation Environment (TOE) framework and the Diffusion of Innovations (DOI) theory. This research model examines factors of technological context (compatibility, complexity, service quality, security, and relative advantages), organisational context (top management support, organisation size, and technology readiness), environmental context (regulations and competitive pressures), and social context (awareness, trust, and attitude) in regard to the adoption of cloud computing. Ultimately, this study enhances the decision-making of the Saudi government through understanding and highlighting the most important factors that influence the adoption of cloud computing in an e-government context. This is a position paper, reporting on the work in progress. The findings of this study will be useful for the researchers who considers suitability of different methodological approaches for cloud computing adoption and evaluation.
\end{abstract}

Keywords—cloud computing, adopting, e-government, online services.

\section{INTRODUCTION}

With the development of computer science and the Internet, cloud computing has become an important part of the development of information systems. Cloud computing has been defined as an application that enables a user to access any network everywhere and share configurable computing resources (such as networks, servers, storage, applications, and services) through easy access to information with minimal management. The adoption of cloud computing in e-government in the public sector provides a wide range of benefits, such as improved efficiency, facilitating the completion of operations, and providing high-quality services. Cloud computing has revolutionised the adoption of IT in various sectors.

In context, cloud computing has several features which define its function and which organisations have taken advantage of. One of the most significant benefits of cloud computing is online storage as a framework for technology [1]. This can use networks to connect servers and storage devices, which facilitates deployment of storage solutions. In addition, it gives online service providers the ability to assist customers around the world in order to turn their aspirations into achievements by taking advantage of the efficiency and speed of the Internet. More specifically, the cloud computing concept allows users to access information and data at any time, from anywhere without restrictions or requirements for hardware equipment [3]. Generally, services management is a requirement in cloud computing, particularly to allow personal computers to access cloud based services over the Internet. In recent years, this has attracted greater attention of investors. For example, recent rejuvenation of Microsoft's fortunes can be attributed in a large part to the success of their Azure cloud-services business [11]. As such, cloud services can contribute to the flexibility of an organisation's computing infrastructure, increase their capacity to deliver eservice solutions, while reducing their IT infrastructure costs; even if demand increases [2].

Moreover, developing countries, especially Saudi Arabia, face many challenges in the digital divide, which refers to the gap between access to e-services provided by government organizations and their citizens. Therefore, the Saudi e-government system is still in the initial stages of adopting cloud computing for the provision of electronic services. Consequently, e-government systems suffer from weaknesses in providing services and technical assistance through the portal of e-services. One major challenge that faces Saudi e-government services is the lack of IT infrastructure in their e-government systems. For example, citizens are not able to access e-government services easily, say on a mobile phone platform or tablet computer. Also, the quality of e-government services does not match the expectations of citizens [7]. Other challenges influencing the adoption of cloud computing in e-government systems include availability, trust, cost, and the issue of security.

Based on the current implementation of Saudi egovernment systems, most Saudi government agencies lack the quality of their own services on the Internet. However, most of these services are incomplete due to poor infrastructure, while some government agencies seek solutions that reduce the cost of developing IT infrastructure and improve services delivery. This research paper seeks to answer the question:

- What are the factors that affect the adoption of cloud computing on e-government services in Saudi Arabia from an IT employer's perspective?

The findings of this study identified new factors that are likely to influence the adoption of cloud computing on egovernment services. Moreover, this paper proposes a comprehensive new model to adopt and verify the factors that most affect the adoption of cloud computing. 


\section{LITERATURE REVIEW}

Most current cloud studies are exploratory or descriptive in nature. A number of researchers have previously made several attempts to help organisations to adopt cloud computing. Alkhwaldi, et. al. [4] conducted a study that investigated the factors that affect cloud computing, such as costs, benefits and cloud-based cloud security, at the organisational level within SMEs. Similarly, a study by Lal and Bharadwaj [22] focused on integrating an existing e-government system with cloud computing using the TOE model [6]. Martin's et al. [9] found that awareness, relative advantage, cultural environment and organisational attitudes have an influence on the intention of organisations to adopt cloud computing [7]. Martin's et al. [9] suggested that the measurement of any success of new technologies depends on the context of the system or organisations.

Thus, most of these studies have been focused on identifying the factors from the organisational perspective, whereas there is a need to consider factors influencing organisations perspective to adopt a new technology from the technology perspective.

Some scientists and researchers have discussed cloud computing contributions in regard to how to provide computer infrastructure and services. For example, Al Badi et al. [11] proposed a financial incentives model for adopting cloud computing based on the TOE model. In their extensive study of the determining factors, many interviews were conducted with employees in the government of Oman. This model explores factors in the organisational context that have a direct impact in either restricting or helping to adopt technological innovation. Alshura et. al. [12] agreed that supporting the regulatory environment is an important factor in the adoption of innovation to be conducive to the achievement of the organisation's objectives. Hence, it is necessary to determine the factors that impact on how to increase the efficiency and achievement of an organisation's objectives that focus on adoption of cloud computing.

\section{E-GOVERNANCE IN SAUDI ARABIA}

The Saudi government established the e-government Yesser program in 2005 to increase the efficiency of the public sector's productivity and providing better services for individuals and business [8]. The objective of this national egovernment program is transforming the government sector into an information society. However, in Saudi Arabia, IT is still a relatively modern technology compared to other developed countries, such as the United States, the United Kingdom and Germany [15]. Therefore, many sectors, from both public and private organisations, have invested in information technology systems in one way or another to develop and improve the efficiency and effectiveness of eservices, which has made developing such services an important government priority.

Saudi Arabia has faced obstacles to the development of the ICT due to lack of IT infrastructure. According to a United Nations e-government survey in 2018, based on the egovernment Development Index, the Saudi e-government is ranked No. 52, achieving a high indicator of 0.7119 [16]. A study conducted by Al-Nuaim, [17] to evaluate the Saudi eGovernment services providers indicated that nine Saudi ministries provide e-Government services, also indicating that $41 \%$ of these ministries were not implementing full egovernment services.

Moreover, a study conducted by [18] ten Saudi ministries provide e-government services, indicating that $45.4 \%$ of these ministries were completely or partially at the egovernment services presence stage; and only three Saudi ministries provide e-government services, which represents that $13.6 \%$ were at the Saudi e-government services interaction level. Therefore, the Saudi government seeks to encourage innovation and investment which adopts modern and advanced ICT. Therefore, there are many problems facing the adoption of cloud computing in Saudi Arabia, which is one of the most complex countries because of the diversity of its problems [19]. These problems are not limited to scientific challenges, but also include, importantly, cultural differences, educational levels, political systems, and social levels.

\section{THEORETICAL FOUNDATION}

Over the past two decades, intensive research has been conducted using different models to investigate how to adopt different types of information technology in organisations [15]. Some research considers the adoption of new technologies using the TOE Model, which allows us to identify the most important factors affecting adoption [23].

\section{A. Diffusion of Innovation Theory (DOI)}

Diffusion of innovation (DOI) was first designed by Rogers in the 1960s, the purpose of which was to study the dissemination of innovation in society. In 1995, the DOI theory model was further developed by Rogers [24] to analyse and discuss an influence adopting new technology through its implementation in electronic systems. The DOI theory is an important model for determining the factors that influence innovation adoption in order to provide a better environment for Information system (IS) research and improve the ability to measure users' perceptions of IT innovations. The literature on DOI frameworks suggests that the factor of observability can be measured by the adopted technology from the perspective of the user or organisation.

As such, it will be useful to examine this observability factor to achieve the objectives of this study. In addition, other variables in DOI are experimental factors, which are commensurate with the intention of organisations to adopt new technologies, including e-government systems.

\section{B. Technology-Organisation-Environment(TOE) Framework}

Tornatzky and Fleischer designed the TOE framework in 1990. This framework aims to identify the components of the organisation that have an impact on the adoption and implementation of technological innovations [25]. The TOE model consists of three elements, which revolve around technological problems, internal and external factors, and organisations [9]. The first element refers to the technological issues facing the organisation that intends to adopt a technology, such as IT infrastructure, security and quality of services. The second factor refers to internal and external factors that have an impact on the organisation, such as competition in the market and regulations and policies, while the third factor describes the organisation in terms of the 
nature of its activity, size and the structure of organisations [26].

In the TOE framework, there is a relationship with Rogers' theory of innovation diffusion, by focusing on both individual and organisational characteristics. Moreover, through studies that have been conducted, it is seen that the TOE framework assists in the adoption of technology in organisations.

\section{RESEARCH MODEL}

The proposed research model in this paper seeks to examine the influencing factors on the adoption of cloud computing in e-government in Saudi Arabia. The model is developed on the basis of four theoretical concepts:

\section{a) Technological context \\ b) Organisational context \\ c) Environmental context \\ d) Social context}

This model joins a more theoretical perspective to have a comprehensive model for understanding the factors that influence the adoption of information technology. The theoretical models are the Technology and Environment Organisation (TOE) model integrating the critical factors from the Diffusion of Innovations (DOI) theory for a better understanding of regulatory decisions and the factors related to adopting of cloud computing in e-government in Saudi Arabia.

This study proposes a model that identifies the factors that most influence the adoption of cloud computing in Saudi egovernment (ACCE-GOV) sector. Therefore, the goal of this research is to present an integrated model (ACCE-GOV) that attempts to find how it is possible to enhance the adoption of cloud computing in the government sector in Saudi Arabia. As a result, the proposed model combines the factors, as shown in Fig 1.

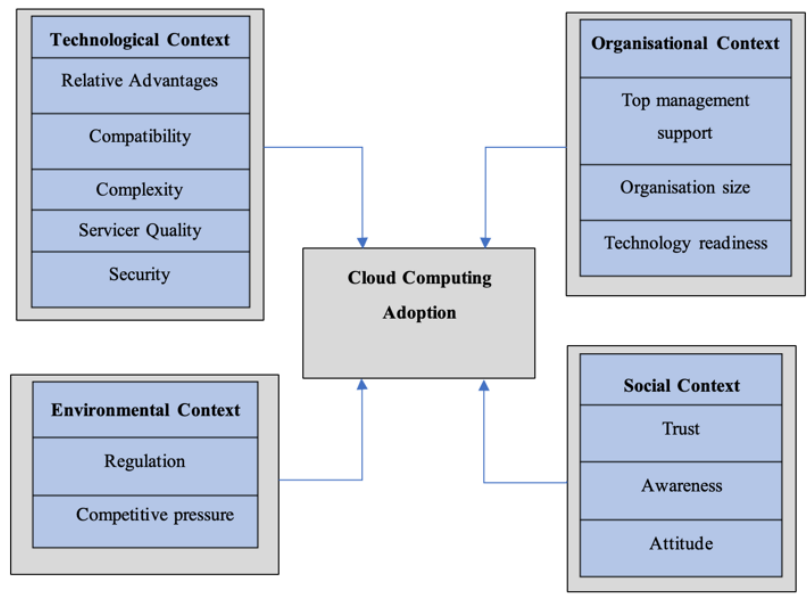

Fig. 1. The conceptual model for the adoption of cloud computing in Saudi e-government ( $A C C E-G O V)$

\section{A. The organisational context}

- Top management support: considers how the role of how top management has an important influence on the adoption of cloud computing. Therefore, top management support refers to the role of top managers in supporting decision-making that adopts and implements information technology in order to seek to develop the organisation with technological investments [7]. Based on our literature review concerning the adoption of cloud computing, it is found that top management support is one of the most important factors affecting the adoption of IT at the organisational level [20]. In the context of egovernment, the participation of top management in the development of ICT has led to a positive attitude related to the decisions made on the adoption of cloudbased services [22]. Top management support encourages IT employees to adopt the new technology as a means of improving organisational effectiveness.

- Organisational size: one of the factors that can affect the adoption of cloud computing is the organisation's size. Studies have shown that bigger organisations need to expand into using new technology, which can influence them to adopt cloud computing for service delivery [29]. Moreover, organisational size, according to the TOE structure, was one of the most important factors influencing the organisations' intention to accept innovation [30]. Kurdi et al. [7] have also found that the organisation's size has a positive impact on investment in cloud computing technology. Low et al. [32] found that the organisation's size will affect the adoption of new technology. Small organisations tend not to adopt new technologies, because they have concerns about the failure to invest in new technologies due to limited resources and experience. Therefore, the impact of organisational size is one of the factors that have an important impact on the adoption of cloud computing in e-government.

- Technology readiness: is one of the critical factors that will influence the adoption of cloud computing in organisations [28]. Technology readiness refers to the maturity level of the network technologies and enterprise systems that can adopt cloud computing. Technology readiness has a significant impact on leadership when it comes to making a decision on adopting an innovation [35]. Governments in developing countries face difficult social, economic and political constraints that limit their ability to invest in expensive information systems to compete on the world stage. A study by [11] focused on integrating the existing e-government system and found that in the IT of ministries, $62.8 \%$ had infrastructural weakness and $46.6 \%$ of ministries had a lack of security and privacy of information, which has an influence on the intention of organizations in the adoption of cloud computing. In any organisation, having a strong ICT infrastructure is an important factor for success. Azam [31] found that the readiness of an ICT infrastructure helps in the adoption of new technologies. Government organisations that give full support encourage the promotion of the development of technology and communications in government agencies. Organisations in Saudi Arabia have a lack of technical readiness, which means that the infrastructure of technology and human resources related to IT makes it difficult to adopt new technology. 


\section{B. Technological Context}

- Compatibility: refers to "... the degree to which an innovation is perceived as consistent with the existing values, past experiences, and needs of potential adopters[37]." The compatibility of processes with the standards of organisations is considered an influential technological factor in the adoption of new technologies in an organisation [38]. Based on the theory of diffusion of innovation [34], compatibility is one of the important factors of the major predictions that affect the adoption of information systems in organisations. Competent innovations facilitate consumer understanding and use of technology, reflecting on organisations' improved service delivery and technology development services. Cloud computing needs to be compatible with existing systems, as some organisations suffer from lack of infrastructure

- Complexity: described as “... the degree to which an innovation is perceived as relatively difficult to understand and use" [32]. Recent studies state that understanding the level of perceived difficulty in adoption of cloud computing will enhance the organisation's intention to either adopt or ignore it [36]. In fact, the adoption of cloud computing contributes to e-services, saving the time to perform tasks, which increases the efficiency of data transfer [33]. One of the benefits of adopting cloud computing is the ease of use. Cloud computing is inversely proportional to complexity in the implementation. Small organisations perceive cloud computing as highly complex, and this perception is due to lack of skills, and availability of IT resources to evaluate cloud computing. Thus, most organisations in Saudi Arabia are still concerned about adopting new technology, because of the complexity associated with this adoption.

- Service quality: refers to the result of the comparison between the service provider and customer satisfaction with the service and their understanding of the way the service was implemented [42]. The service quality is an important factor for higher levels in the adoption of new technologies [43]. Alshehri et al. [14] found that culture in Saudi Arabia plays a role in decision-makers in their intention to adopt new systems. Moreover, the culture of users around the use of the Internet in Saudi Arabia can contribute to the development of modern technologies in providing better services. For this reason, the use of the Internet is about $96 \%$ on an average rate of 1-5 hours. There are many IS studies that have discussed measuring service quality by attention to various aspects of quality. Jain and Aggarwal [39] state that the service quality could enhance user satisfaction in enabling them to adopt online services. High service quality increases intention to adopt and use egovernment systems. Service quality has received great attention in various sectors of the IS field. Therefore, service quality has an influence on an organisation's management to adopt cloud computing services.
- Relative Advantage: refers to "... the degree to which an innovation is perceived as being better than the idea it supersedes" [37]. Comparative advantage drives organisations to switch to cloud computing if their adoption can reduce operational costs and improve service delivery [46]. One of the most important innovations of innovation theory is perceived relative advantages [28]. Relative advantage supports a positive and important relationship as to the benefits of cloud computing. For example, easy access to services, reduced cost [47]. Therefore, relative advantages are likely to affect organisations' decisions that support the adoption of cloud computing, which gives an appropriate impression about the future of cloud computing. In fact, organisations need to avoid the costs associated with systems and the maintenance of IT infrastructure. Thus, in Saudi government organisations they are, through cloud computing, able to increase resources and infrastructure that meet the requirements in order to provide better services.

- Security: many researchers have identified that security issues are one of the most influential elements of users' trust in technology. Security refers to the degree to which a user and organisation's information is safe and protected by the cloud storage provider [28]. Research also suggests that they should consider the technical measures based on policies and regulations to protect data, in order to prevent them from falling into unauthorised hands. Senyo et al. [43] state that governments need to put in place penalties to deter illegal access to data. This type of legislation contributes to increasing the trust of citizens in adopting e-government services. Security is an important concern in the adoption of cloud computing in e-government services [49]. Users still suffer from low level of protection of personal information and sharing information raises concerns of theft and lack of trust in online services. E-government services in developing countries have suffered from security issues, which leads to a lack trust for online services by citizens.

\section{Environmental context}

- Regulations: refer to the rules and policies that are applied by organisations in order to persuade there to be an increase in the adoption of IT innovations [50]. For this, governments have the ability to promote the adoption of cloud computing by drafting regulations in order to encourage organisations to invest. The government regulations have a positive effect by reducing the restrictions related to the adoption of new technologies [31]. Karim and Rampersad [34] have stated that compliance with the government's regulatory and legal frameworks is supportive of cloud adoption. Cloud providers provide a guarantee that the data are not available to other countries in order to comply with the laws and regulations. The organisation's regulations should fit with the organisations' intent to adopt cloud computing.

- Competitive pressures: refers to the level of pressure felt by organisations to increase demand by effectively providing services to users [31]. Therefore, one of the most important steps to achieving the 
objectives of the organisation should be keeping pace with information technology [51]. The competitive pressure to achieve the vision of the organisation is an important factor in the adoption of information technology. Previous studies [47] have discussed that information technology is characterised by rapid change. Organisations are increasingly faced with the development of the organisation's technical qualities and training related to the next generation of technologies. Thus, competitive pressure in organisations requires to significantly understand the market's requirements and increase operational efficiency to enhance the adoption and the advantages of new technology.

\section{Social Context}

- Trust: can be generally understood as "The degree to which people trust e-Government policy and service that can be received from another party" [28]. Although trust in technology differs from the concept of trust in general, researchers point out that trust in technology exists when users' expectations are met by interacting with technology having reliability [45]. Trust is a crucial factor in influencing adopting new technology. Service providers attempt to build trust on all levels of online transactions through effective service quality and ease of use [52]. Trust has a major impact on online services. Governments provide adequate services in a way that is appropriate to the levels of the underdeveloped users in order to increase the adoption of the e-services and which contributes to the citizens' trust [50]. It is difficult for cloud service providers to determine the location of data storage because of the lack of infrastructures in these countries, so they have to store data in foreign locations.

- Awareness: refers to "An understanding of the activities of others, which provides a context for your own activity" [38]. Awareness plays an important role in identifying the characteristics of new technologies from other technologies and how they are presented to investors. The government seeks to increase citizens' awareness to encourage citizens to adopt egovernment services [55]. According to [53] cloud computing providers have identified that awareness is one of the barriers that affect the adoption of cloud computing in e-government. One of the major concerns regarding the deployment and use of cloud computing is the lack of awareness of the existence of related services [49]. A study conducted by [14] showed the adoption and use of e-government in Saudi Arabia from the perspective of users and found that e-government use accounted for $85 \%$ of users and satisfaction rate was $75 \%$ of services delivery in the use of the Saudi Arabia e-government portal "Saudi.gov.sa". In addition, the number of transactions conducted for many basic services was low because there are technical problems in the data centre in most of the ministries that provide electronic services. Furthermore, governments need to pay attention to e-government initiatives to ensure the adoption of effective technologies that improve the delivery of e-government services to meet user satisfaction.
- Attitude: refers to "positive attitudes toward the system and willingness to participate in the implementation and to accept the change brought about by the system" [48]. Cloud computing dramatically expands data storage capacity, making it easier to manage and synchronise data in different business environments, and impact organisational attitude about the benefits of cloud computing [57]. Attitudes have an impact on the perception of organisational behaviour towards cloud computing. Previous research suggested that decision-makers' attitudes towards adopting new technologies play an important role in determining their behaviour [45]. Governments give more attention to e-government services that are reliant on the latest technology to provide a service that provides easy access and high level of service quality. In developing countries, especially in Saudi Arabia, there are attempts to shift e-government systems to adopt cloud computing. This has led to better service while converting the organisational attitude towards cloud computing.

\section{METHODOLOGY}

In this study, the methodology that we will apply is mixed methods. Both quantitative (survey) and qualitative (semistructured interviews) methods will be used in a complementary manner. In the IS research field, a combined methodology of both quantitative and qualitative analysis is more common.

The quantitative method will be the main method of data collection utilising a survey questionnaire. The questionnaire will be distributed in different government organisations in Saudi Arabia, electronically and manually, so as to be more comprehensive. The target sample size will be around 400 responses. In this study will identify the respondents in the organization who are most in IT employers and top management of an organisations. To target respondents who assume the role of a key informant in knowledgeable about cloud computing to increase content validity. we encourage all participants that should be filled out this survey have familiar cloud computing by providing a description of cloud computing. The data analysis of the survey will be the research model, validated using descriptive statistics as well as the structural equation model (SEM).

In the second stage, the qualitative method will be conducted with top managers, IT management professionals and IT department staff in order to understand in-depth the most important factors affecting the adoption of cloud computing from a managerial perspective. Face-to-face interviews will conduct by researcher which will semistructured questions use during the interviews. Interview questions include general questions asking to describe the issues and challenges you face in your current online system in term and their experience with the adoption cloud computing, as well as sub-questions such as the reasons that prevent to adopt cloud computing in government organisations in Saudi Arabia. also, which factors that impact the adoption of cloud computing in government organisations. The notes taken from the field will be organised and coded into NVivo software. These codes will be used to generate categories or themes for analysis. 


\section{CONCLUSION}

E-government in Saudi Arabia is still in the initial stage of adopting cloud computing, which has suffered from a lack of IT infrastructure. To understand these challenges, this study investigates those factors that prevent organisations from adopting cloud computing. Moreover, we develop a new comprehensive model for the adoption of cloud computing in Saudi e-government, in order to identify and gain an in-depth understanding of the biggest factors influencing an organisation's decision to adopt cloud computing. Finally, this comprehensive model is a universal model that will have an impact on e-government decision makers and ICT managers in the Saudi government in public sector by identifying the factors influencing the adoption of cloud computing in order to improve the provision of effective eservices over the Internet.

\section{REFERENCES}

[1] C. Stergiou, K. E. Psannis, B. G. Kim, and B. Gupta, "Secure integration of IoT and Cloud Computing," Futur. Gener. Comput. Syst., vol. 78, no. December, pp. 964-975, 2018.

[2] V. Chang, R. J. Walters, and G. Wills, "The development that leads to the Cloud Computing Business Framework," Int. J. Inf. Manage., vol. 33, no. 3, pp. 524-538, 2013.

[3] R. Kaur and A. Kaur, "A Review Paper on Evolution of Cloud Computing, its Approaches and Comparison with Grid Computing," Int. J. Comput. Sci. Inf. Technol., vol. 5, no. 5, pp. 6060-6063, 2014.

[4] A. Al-Badi, A. Tarhini, and W. Al-Kaaf, "Financial Incentives for Adopting Cloud Computing in Higher Educational Institutions," Asian Soc. Sci., vol. 13, no. 4, p. 162, 2017.

[5] R. Martins, T. Oliveira, and M. A. Thomas, "An empirical analysis to assess the determinants of SaaS diffusion in firms," Comput. Human Behav., vol. 62, pp. 19-33, 2016.

[6] H. J. Wang and J. Lo, "Adoption of open government data among government agencies," Gov. Inf. Q., vol. 33, no. 1, pp. 80-88, 2016.

[7] A. Alkhwaldi, M. Kamala, and R. Qahwaji, "From e-govemment to cloud-government: Challenges of Jordanian citizens' acceptance for public services," 2017 12th Int. Conf. Internet Technol. Secur. Trans. ICITST 2017, pp. 298-304, 2018.

[8] O. Ali, J. Soar, H. McClymont, J. Yong, and J. Biswas, “Anticipated Benefits of Cloud Computing Adoption in Australian Regional Municipal Governments: An Exploratory Study," Proc. 19th PacificAsian Conf. Inf. Syst. (PACIS 2015), no. January 2016, pp. 1-17, 2015.

[9] C. Mutimukwe, E. Kolkowska, and Å. Gr, "Electronic Government," vol. 10428, pp. 324-335, 2017.

[10] R. Kurdi, E. Nyakwende, and D. Al-Jumeily, "E-Government Implementation and Readiness: A Comparative Study between Saudi Arabia and Republic of Korea," Proc. - 2015 Int. Conf. Dev. eSystems Eng. DeSE 2015, pp. 279-284, 2016.

[11] F. N. Alqahtani, "Identifying the Critical Factors that Impact on the Development of Electronic Government using TOE Framework in Saudi E-Government Context: A Thematic Analysis," PQDT - UK Irel., no. October, 2016.

[12] H. F. Lin, "Understanding the determinants of electronic supply chain management system adoption: Using the technology-organizationenvironment framework," Technol. Forecast. Soc. Change, vol. 86, pp. 80-92, 2014.

[13] A. M. AlBar and M. R. Hoque, "Factors affecting cloud ERP adoption in Saudi Arabia: An empirical study," Inf. Dev., 2017.

[14] M. Alshura, T. World, I. Science, M. Abughazaleh, and M. Alhadi, "Critical Success Factors for Adopting Cloud Computing in the Pharmaceutical Manufacturing Companies .," no. February, 2018.

[15] T. Al-Tourki, H. F. El-Sofany, A. Al-Sadoon, and H. Al-Howimel, "Egovernment in Saudi Arabia: Barriers, Challenges and its Role of Development," Int. J. Comput. Appl., vol. 48, no. 5, pp. 975-888, 2012.

[16] U. Nations, "E-Government Survey 2018," United Nations, 2018. [Online]. Available: https://publicadministration.un.org/egovkb/enus/reports/un-e-government-survey-2016.

[17] H. Al-Nuaim, “An Evaluation Framework for Saudi E-Government," J. E-Government Stud. Best Pract., vol. 2011, pp. 1-12, 2011.
[18] Ali S. AlSoma, "The Saudi E-Government program," Ministry of Communications and IT. [Online]. Available: https://www.google.com/search?q=ten+Saudi+ministries+provide+egovernment + services $\% 2 C \& r l z=1 C 5 C H F A \_$enSA759SA759\&oq $=$ten + Saudi + ministries + provide $+\mathrm{e}-$

government + services $\% 2$ C\&aqs $=$ chrome...69i57.901j0j7\&sourceid $=\mathrm{ch}$ rome\&ie $=\mathrm{UTF}-8$.

[19] M. Alshehri and S. Drew, "A Comprehensive Analysis of Egovernment services adoption in Saudi Arabia: Obstacles and Challenges," Int. J. Adv. Comput. Sci. Appl., vol. 3, no. 2, 2012.

[20] K. E. Ali, S. A. Mazen, and E. E. Hassanein, "A Proposed Hybrid Model For Adopting Cloud Computing In E-Government," Futur. Comput. Informatics J., 2018.

[21] F. Mohammed, O. Ibrahim, and N. Ithnin, Factors influencing cloud computing adoption for e-government implementation in developing countries: Instrument development, vol. 18, no. 3. 2016.

[22] F. Durao, J. F. S. Carvalho, A. Fonseka, and V. C. Garcia, "A systematic review on cloud computing," J. Supercomput., vol. 68, no. 3, pp. 1321-1346, 2014.

[23] O. M. Ahmad and Z. R. Khan, "The Cloud Computing: A Systematic Review," Int. J. Innov. Res. Comput. Commun. Eng. (An ISO Certif. Organ., vol. 3, no. 5, pp. 4066-4075, 2015.

[24] D. Aizstrauta, E. Ginters, and M. A. P. Eroles, "Applying theory of diffusion of innovations to evaluate technology acceptance and sustainability," Procedia Comput. Sci., vol. 43, no. C, pp. 69-77, 2015.

[25] M. Tornatzky and L. Fleischer, The processes of technological innovation. Lexington, Mass, 1990.

[26] H. P. Borgman, B. Bahli, H. Heier, and F. Schewski, "Cloudrise: Exploring cloud computing adoption and governance with the TOE framework," Proc. Annu. Hawaii Int. Conf. Syst. Sci., pp. 4425-4435, 2013

[27] P. Lal and S. S. Bharadwaj, "Understanding the impact of cloud-based services adoption on organizational flexibility: An exploratory study," J. Enterp. Inf. Manag., vol. 29, no. 4, pp. 566-588, 2016.

[28] M. A. Wahsh and J. S. Dhillon, "An investigation of factors affecting the adoption of cloud computing for E-government implementation," 2015 IEEE Student Conf. Res. Dev. SCOReD 2015, pp. 323-328, 2015.

[29] A. Abdollahzadehgan, A. Razak, C. Hussin, M. M. Gohary, and M. Amini, "The Organizational Critical Success Factors for Adopting Cloud Computing in SMEs," J. Inf. Syst. Res. Innov., vol. 4, no. 1, pp. 67-74, 2013.

[30] N. Alkhater, G. Wills, and R. Walters, "Factors Influencing an Organisation's Intention to Adopt Cloud Computing in Saudi Arabia," 2014 IEEE 6th Int. Conf. Cloud Comput. Technol. Sci., pp. 1040-1044, 2014

[31] H. O. Awa and O. U. Ojiabo, "A model of adoption determinants of ERP within T-O-E framework," Inf. Technol. People, vol. 29, no. 4, pp. 901-930, 2015.

[32] C. Low, Y. Chen, and M. Wu, "Understanding the determinants of cloud computing adoption," Ind. Manag. Data Syst., vol. 111, no. 7, pp. 1006-1023, 2011.

[33] J. Sun, "Tool choice in innovation diffusion: A human activity readiness theory," Comput. Human Behav., vol. 59, pp. 283-294, 2016.

[34] H. T. Tsou and S. H. Y. Hsu, "Performance effects of technologyorganization-environment openness, service co-production, and digital-resource readiness: The case of the IT industry," Int. J. Inf. Manage., vol. 35, no. 1, pp. 1-14, 2015.

[35] Y. Liang, G. Qi, K. Wei, and J. Chen, "Exploring the determinant and influence mechanism of e-Government cloud adoption in government agencies in China," Gov. Inf. Q., vol. 34, no. 3, pp. 481-495, 2017.

[36] M. S. Azam, "E-Services Adoption: Processes by Firms in Developing Nations," Adv. Bus. Mark. Purch., vol. 23, pp. 7-290, 2015.

[37] E. Rogers, " Attributes of Innovations and Their Rate of Adoption ". Library of Congress Cataloging-in-Publication Data, 1995.

[38] F. Mohammed, A. I. Alzahrani, O. Alfarraj, and O. Ibrahim, "Cloud Computing Fitness for E-Government Implementation: ImportancePerformance Analysis," IEEE Access, vol. 6, pp. 1236-1248, 2017.

[39] F. Karim and G. Rampersad, "Factors Affecting the Adoption of Cloud Computing in Saudi Arabian Universities," Comput. Inf. Sci., vol. 10, no. 2 , p. $109,2017$.

[40] I. Khalil, "Influence of Culture on e-Government Acceptance in Saudi Arabia," arXiv Prepr. arXiv1307.7141, no. June, p. 68, 2012.

[41] J. W. Lian, D. C. Yen, and Y. T. Wang, "An exploratory study to 
understand the critical factors affecting the decision to adopt cloud computing in Taiwan hospital," Int. J. Inf. Manage., vol. 34, no. 1, pp. 28-36, 2014.

[42] A. Parasuraman, V. A. Zeithaml, and L. L. Berry, "Reassessment of Expectations as a Comparison Standard in Measuring Service Quality: Implications for Further Research," J. Mark., vol. 58, no. 1, p. 111, 1994.

[43] P. Carswell, "The development story of creating a whole of system cloud-based platform for supporting quality improvement for integrated care," Int. J. Integr. Care, vol. 17, no. 3, p. 123, 2017.

[44] P. Jain and V. S. Aggarwal, "Developing a service quality scale in context of organized grocery retail of India," Manag. Decis., vol. 56, no. 9, pp. 1969-1990, 2018.

[45] R. Santa, J. B. MacDonald, and M. Ferrer, "The role of trust in eGovernment effectiveness, operational effectiveness and user satisfaction: Lessons from Saudi Arabia in e-G2B," Gov. Inf. Q., no. October, pp. 1-12, 2018.

[46] S. Dash and S. K. Pani, "E-Governance Paradigm Using Cloud Infrastructure: Benefits and Challenges," Procedia Comput. Sci., vol. 85, no. Cms, pp. 843-855, 2016.

[47] E. A. Abu-Shanab, "E-government familiarity influence on Jordanians' perceptions," Telemat. Informatics, vol. 34, no. 1, pp. 103-113, 2017.

[48] P. K. Senyo, J. Effah, and E. Addae, "Preliminary insight into cloud computing adoption in a developing country," J. Enterp. Inf. Manag., vol. 29, no. 4, pp. 505-524, 2016.

[49] P. Joshi and S. Islam, "E-Government Maturity Model for Sustainable E-Government Services from the Perspective of Developing Countries," Sustainability, vol. 10, no. 6, p. 1882, 2018.

[50] F. Mohammed, O. Ibrahim, M. Nilashi, and E. Alzurqa, "Cloud computing adoption model for e-government implementation," Inf. Dev., vol. 33, no. 3, pp. 303-323, 2017.

[51] C. fei Chen, X. Xu, and L. Arpan, "Between the technology acceptance model and sustainable energy technology acceptance model: Investigating smart meter acceptance in the United States," Energy Res. Soc. Sci., vol. 25, pp. 93-104, 2017.

[52] J. M. Hansen, G. Saridakis, and V. Benson, "Risk, trust, and the interaction of perceived ease of use and behavioral control in predicting consumers' use of social media for transactions," Comput. Human Behav., vol. 80, pp. 197-206, 2018.

[53] M. Tang, X. Dai, J. Liu, and J. Chen, "Towards a trust evaluation middleware for cloud service selection," Futur. Gener. Comput. Syst., vol. 74, pp. 302-312, 2017.

[54] A. Albesher, "Trust as a source of long-term adoption of egovernment 2016 ", no. September, 2015.

[55] A. A. Oni, S. Oni, V. Mbarika, and C. K. Ayo, "Empirical study of user acceptance of online political participation: Integrating Civic Voluntarism Model and Theory of Reasoned Action," Gov. Inf. Q., vol. 34, no. 2, pp. 317-328, 2017.

[56] P. Joshi, S. Islam, and S. Islam, "A Framework for Cloud Based EGovernment from the Perspective of Developing Countries," Futur. Internet, vol. 9, no. 4, p. 80, 2017.

[57] M. S. Wong and S. Jackson, "User satisfaction evaluation of Malaysian e-government education services," 2017 Int. Conf. Eng. Technol. Innov. Eng. Technol. Innov. Manag. Beyond 2020 New Challenges, New Approaches, ICE/ITMC 2017 - Proc., vol. 2018-Janua, pp. 531537,2018 